\title{
PROGRAMA DE EXTENSÃO EM GESTÃO CONTÁBIL: CONSTRUINDO DIÁLOGO ENTRE UNIVERSIDADE E COMUNIDADE
}

\author{
Carolina Citadin Milaneze ${ }^{1}$, Júlia Constante Pereira ${ }^{2}$, Fernanda Pires da Rosa ${ }^{3}$, Milla Lúcia \\ Ferreira Guimarães ${ }^{4}$, Andréia Cittadin ${ }^{5}$
}

\section{RESUMO}

As universidades comunitárias possuem a finalidade de proporcionar atividades de ensino, além de produzirem novos conhecimentos por meio da pesquisa e dedicarem importante esforço para a extensão com intuito de compartilhar o conhecimento científico construído na academia com a sociedade, a qual oferece novos fenômenos para a investigação científica. $\mathrm{O}$ objetivo do artigo consiste em relatar o início das atividades de um programa de extensão universitária na área de Ciências Contábeis. O estudo é qualitativo, descritivo e elaborado mediante pesquisa documental e participante. O Curso de Ciências Contábeis da UNESC, por meio do Programa de Extensão em Gestão Contábil (PEGC), busca promover a aproximação de docentes e discentes com a comunidade regional no intuito de oportunizar a indissociabilidade entre ensino, pesquisa e extensão. No sentido de construir, produzir e socializar o conhecimento vivenciado no ambiente universitário e concretizá-lo por meio das práticas extensionistas, o PEGC oportunizará a transformação social e a formação de jovens, não só competentes profissionalmente, mas também conscientes de sua atuação como cidadãos. Os resultados evidenciam algumas possibilidades para promover a interação e a troca de saberes entre a comunidade acadêmica e a sociedade na área de contabilidade, sendo essa uma das funções que compõem os pilares da instituição universitária.

Palavras-chave: Extensão; Universidade Comunitária; Ciências Contábeis.

\footnotetext{
ABSTRACT

The communities universities have the purpose of providing educational activities, and, produce new knowledge through research and to devote significant effort to the extension aiming to share scientific knowledge built in the university with society, which offers new phenomena for scientific research. The objective of this article is to report the beginning of activities of a university extension program in the field of Accounting. The study is qualitative, descriptive and prepared by documentary research and participant. The

${ }^{1}$ Graduanda em Ciências Contábeis e Direito pela Universidade do Extremo Sul Catarinense - UNESC. E-mail: carolcmilaneze@hotmail.com.

${ }^{2}$ Graduanda em Ciências Contábeis pela Universidade do Extremo Sul Catarinense - UNESC.

${ }^{3}$ Bacharel em Ciências Contábeis pela Universidade do Extremo Sul Catarinense - UNESC.

${ }^{4}$ Possui Graduação em Ciências Contábeis pela Fundação Educacional de Criciúma (1992), Especialização em Didática e Metodologia do Ensino Superior pela UNESC (2004) e Mestrado em Educação pela UNESC (2014). Atualmente é professora titular da Universidade do Extremo Sul Catarinense. Integrante dos Grupos de Pesquisa: Núcleo de Estudos Contábeis (NECON) e Núcleo de Estudos Organizacionais (NEGEO). Coordenadora de Extensão da Unidade Acadêmica de Ciências Sociais Aplicadas da UNESC (Portaria n. 29/2014).

${ }^{5}$ Mestre em Contabilidade pela Universidade Federal de Santa Catarina - UFSC, possui graduação em Ciências Contábeis e especialização em Contabilidade Gerencial pela Universidade do Extremo Sul Catarinense. Atualmente é professora titular e coordenadora de estágio do curso de ciências contábeis da Universidade do Extremo Sul Catarinense. É coordenadora do Programa de Extensão em Gestão Contábil (PEGC) e líder do GP Núcleo de Estudos Contábeis (NECON) e realiza pesquisa em Ciências Contábeis, atuando principalmente nos seguintes temas: contabilidade gerencial, controladoria, gestão de custos, logística e ensino e pesquisa em contabilidade.
} 
Accounting Course of UNESC through the Extension Program in Accounting Management (PEGC) seeks to promote the approach of teachers and students with the regional community in order to create opportunities for indivisibility of teaching, research and extension. In order to build, produce and socialize knowledge experienced in the university environment and achieving it through extension practices, PEGC will promote social transformation and the formation of young people, not only professionally competent, but also aware of their actions as citizens. The results show some possibilities to promote interaction and exchange of knowledge between the academic community and society in the accounting area, which is one of the functions that make up the pillars of the university.

Keywords: Extension; Community University; Accounting Course. 


\section{Revista de Extensão, v. 1, n. 2, 2016}

\section{INTRODUÇÃO}

Atualmente o ensino universitário discute e aprofunda um novo conceito que ultrapassa a transmissão do conhecimento em sala de aula, englobando todos os espaços, formais e informais, para o processo de ensino-aprendizagem. Esta nova postura não se limita ao espaço físico da sala de aula e incorpora a dimensão histórico-social dos sujeitos envolvidos, utilizando-se do tripé indissociável da universidade - o ensino, a pesquisa e a extensão.

A extensão universitária é uma parte indispensável no pensar e fazer acadêmico, assumindo uma luta pela institucionalidade, adotando medidas e procedimentos, redirecionando a política, reafirmado seu compromisso em forma de ações, de igualdade e desenvolvimento social, colocando-se como prática acadêmica interligando a universidade em suas atividades de ensino-pesquisa-extensão com a sociedade.

Pode-se afirmar que extensão é o elo, que associado ao ensino e à pesquisa, vincula a universidade com a sociedade, bastando apenas promover propostas de ações que concretizem a formação acadêmica e a integração entre aluno/professor/universidade/sociedade.

Neste contexto, encontram-se as universidades comunitárias cujo principal diferencial está na inserção junto às comunidades regionais e no seu compromisso com a extensão. Além de divulgar o conhecimento científico pelo ensino e produzir novos saberes por meio da pesquisa, as universidades comunitárias se esforçam para partilhar o conhecimento, a arte e a cultura com as comunidades.

Enquanto universidade comunitária, a Universidade do Extremo Sul Catarinense (UNESC) assume a extensão como dimensão que proporciona aos professores e estudantes o contato com a realidade social, partilhando conhecimento e se retroalimentando nesse diálogo, favorecendo a articulação do ensino e da pesquisa. Esse processo torna-se uma via dupla na qual a universidade além de ensinar, aprende e se reinventa (UNESC, 2015).

Para o curso de Ciências Contábeis da UNESC, a extensão tem por objetivo aprimorar a formação superior voltada às demandas da sociedade, alinhando com a sua missão de formar profissionais competentes, com visão empreendedora e globalizada, comprometidos com o desenvolvimento sustentável nos aspectos econômico, social e ambiental.

Consciente da relevante função educacional e social preconizada pela UNESC e pelo Curso foi apresentado um projeto para a criação de um programa de extensão universitária vislumbrando as potencialidades do Curso de Ciências Contábeis. Assim, esse artigo tem o 


\section{Revista de Extensão, v. 1, n. 2, 2016}

objetivo de relatar o início das atividades de um programa de extensão na área das Ciências Contábeis.

Esta pesquisa torna-se relevante na medida em que pretende provocar nos partícipes do Curso de Ciências Contábeis (gestores, professores e estudantes) o desafio de socializar os conhecimentos adquiridos na universidade com a comunidade regional e, ao mesmo tempo, conhecer a possibilidade de, por meio da extensão, oferecer outro espaço de ensino e aprendizagem, de cooperação e desenvolvimento de competências.

Neste contexto, visando à construção de conhecimentos, a extensão universitária, como processo interdisciplinar, educacional, cultural, científico e político, que promove a inter-relação transformadora entre a universidade e a sociedade, oportuniza o desenvolvimento das ações sociais, melhorando a capacidade técnica e teórica dos estudantes, tornando-a elemento fundamental de formação profissional.

Pesquisas como esta buscam proporcionar aos alunos e futuros profissionais de Ciências Contábeis uma relação próxima à sociedade, além de uma reflexão e a contextualização dos conhecimentos teóricos sobre os processos de ensino e aprendizagem promovidos pela academia. A proposta procura estimular novas investigações e relacionar o tripé ensino, pesquisa e extensão, provocando aos acadêmicos uma reflexão sobre a contribuição da extensão na formação de ações que envolvam várias situações da realidade local e na sua formação de estudante universitário.

Esse artigo está estruturado em cinco seções, incluindo esta de caráter introdutório. A segunda abrange o referencial teórico, que trata da extensão universitária e, em seguida, apresenta-se os procedimentos metodológicos. Na quarta seção expõe-se e discute-se os resultados e, por fim, a quinta seção destina-se às conclusões da pesquisa.

\section{REFERENCIAL TEÓRICO}

O primeiro registro oficial de Extensão Universitária está no Estatuto da Universidade Brasileira no Decreto ${ }^{\circ} 19.851 / 31$, em seu art. 42, no qual a extensão universitária deveria se realizar por meio de curso e conferência de caráter educacional ou utilitário, destinados principalmente à construção de conhecimentos e à resolução de problemas da sociedade e à propagação de um conjunto de pensamentos e princípios de interesse social (BRASIL, 1931).

Este modelo permaneceu até o início dos anos de 1960, quando surgiu a definição das áreas de atuação extensionista. Segundo Síveres (2009 apud SILVA et al., 2011) nessa época se iniciou um modelo de extensão baseado no desenvolvimento da comunidade.

Com a Reforma Universitária de 1968, na tentativa de vincular a extensão à ideia de 


\title{
Revista de Extensão, v. 1, n. 2, 2016
}

compromisso social da universidade, há a formulação de uma nova compreensão de extensão em contraposição com a anterior, sendo colocada como uma prática oficial, permitindo uma abertura no processo de institucionalização, ela ainda aparece "sob a forma de cursos e serviços especiais, as atividades de ensino e os resultados das pesquisas" que estenderão à comunidade (BRASIL, 1968).

Anteriormente, as atividades extensionistas preocupavam-se com a politização dos jovens e a expansão da cultura popular, tomando um formato assistencialista e restringindo-se à prestação de serviço.

De acordo com Cabral (2012), durante a década de 1980, a extensão tomou um lugar de destaque nos estudos. Com o fortalecimento institucional, começou a configurar um novo paradigma para a extensão na busca da construção, ampliação e consolidação da cidadania, em uma ação conjunta das universidades voltadas à população. Assim, a extensão passa, pela primeira vez, como atividade acadêmica no mesmo patamar do ensino e da pesquisa, contribuindo para a indissociabilidade entre ensino-pesquisa-extensão.

Com a criação do Fórum Nacional de Pró-Reitores de Extensão das Universidades Públicas Brasileiras (FORPROEX), em 1987, a concepção de extensão é revisada. O FORPROEX tem como finalidade coordenar as reflexões sobre extensão, discutindo a função social da universidade, aprofundando o debate sobre a sua institucionalização, intensificando e fortalecendo o diálogo político, tanto do ponto de vista administrativo como acadêmico, o que implica a adoção de medidas e procedimentos que redirecionam a própria política das universidades. Assim expressa no I Encontro Nacional de Pró-Reitores de Extensão um novo conceito:

\begin{abstract}
A Extensão Universitária é o processo educativo, cultural e científico que articula o Ensino e a Pesquisa de forma indissociável e viabiliza a relação transformadora entre Universidade e Sociedade. A Extensão é uma via de mão-dupla, com trânsito assegurado à comunidade acadêmica, que encontrará, na sociedade, a oportunidade de elaboração da práxis de um conhecimento acadêmico. No retorno à Universidade, docentes e discentes trarão um aprendizado que, submetido à reflexão teórica, será acrescido àquele conhecimento (FORPROEX, 1987, p. 5).
\end{abstract}

A conceituação de extensão formulada pelo FORPROEX assume a função de produção e de socialização do conhecimento, pretendendo a intervenção, possibilitando na realidade acordos e ações coletivas entre universidade e sociedade. Voltada para uma universidade atenta aos problemas sociais com o objetivo de encontrar soluções por meio da pesquisa aplicada, realimentando processo ensino-aprendizagem como um todo.

O FORPROEX trouxe mais claro os desafios a serem enfrentados pelos avanços da institucionalização da extensão, fato que, mesmo com características favoráveis, encontra 


\section{Revista de Extensão, v. 1, n. 2, 2016}

novos contrapontos. Novos progressos foram estabelecidos pelo MEC, sob forte estímulo e ampla colaboração do FORPROEX, um diálogo que resultou na criação em 1993, das diretrizes políticas para o Programa Nacional de Extensão Universitária (PROEXT), especificando as diretrizes e os objetivos, tipos de ações a serem desenvolvidas e da metodologia adotada, quanto a sua implementação assim como definição dos critérios para o apoio financeiro da extensão universitária.

Outra iniciativa importante foi a elaboração do Plano Nacional de Extensão (PNE), publicado em 1999. Com a intenção de alavancar o desenvolvimento das ideias para uma política nacional de extensão, esse plano permite a unidade nacional dos programas de extensão das universidades brasileiras, a garantia de recursos financeiros, o reconhecimento pelo Poder Público do papel da Extensão na concepção de Universidade Cidadã, a viabilidade de solução de problemas sociais.

Neste contexto, a extensão, no âmbito universitário, oportuniza a reflexão acerca dos significados e importância de suas práticas na medida em que procura alinhar as demandas da sociedade com a sua finalidade primeira de construção de saberes, pautada no tripé ensino, pesquisa e extensão.

\section{PROCEDIMENTOS METODOLÓGICOS}

Esse estudo está delineado com uma abordagem qualitativa. Segundo Oliveira (1997), as pesquisas com abordagem qualitativa permitem descrever uma hipótese complexa, analisar como as variáveis se relacionam, e também interpretar e classificar os procedimentos dinâmicos.

A pesquisa caracteriza-se como descritiva, visto que o artigo buscou relatar o processo de criação do Programa de Extensão em Gestão Contábil do Curso de Graduação em Ciências Contábeis da UNESC. De acordo com Pinheiro (2010), a pesquisa descritiva tem como finalidade a descrição das características de população ou fenômeno específico ou também a determinação das relações entre variáveis.

Em relação aos procedimentos, efetuou-se uma pesquisa documental, que de acordo com Silva e Grigolo (2002) baseia-se em materiais que ainda não receberam um tratamento analítico ou que podem ser relacionados de acordo com os objetivos da pesquisa. Neste estudo foram utilizados as Políticas de Extensão da UNESC, os relatórios dos Programas e Projetos da Unidade Acadêmica de Ciências Sociais Aplicadas e Projeto Pedagógico do Curso de Ciências Contábeis da UNESC. 
Foi realizada pesquisa participante, que consiste na relação entre os indivíduos pesquisadores e os participantes das situações examinadas (GIL, 2002).

A UNESC localiza-se no sul do Estado de Santa Catarina e tem caráter comunitário, abrange em sua missão o ensino, a pesquisa e a extensão como meio de promover a qualidade e a sustentabilidade do ambiente de vida.

Inseridas na Universidade existem quatro unidades acadêmicas, a saber: Ciências Sociais Aplicadas; Ciências da Saúde; Ciências, Engenharia e Tecnologia; Humanidades, Ciências e Educação, que coordenam as atividades ensino, pesquisa e extensão na sua área de atuação (UNESC, 2015).

A Unidade Acadêmica de Ciências Sociais Aplicadas (UNACSA) é composta por Colegiado, Diretoria e Coordenações de Ensino de Graduação, Pesquisa e Pós-Graduação e Extensão. Os cursos que compõem a UNA são: Administração de Empresas, Comércio Exterior, Ciências Contábeis, Direito, Ciências Econômicas, Secretariado Executivo, e Tecnólogos em Gestão, ofertados na modalidade presencial. Na modalidade à distância, a Unidade disponibiliza o curso de graduação em Tecnologia em Gestão Comercial. Possui também um programa de Pós-Graduação Stricto Sensu (Mestrado) em Desenvolvimento Socioeconômico, recomendado pela Capes (UNESC, 2015).

O Curso de Ciências Contábeis da UNESC foi criado em 1975, funciona no período noturno, com oferta de 108 vagas semestrais.

\section{APRESENTAÇÃO E ANÁLISE DOS RESULTADOS}

\subsection{A extensão na UNESC: uma universidade comunitária}

A Resolução $n^{\circ}$. 12/2015 do Conselho Universitário (CONSU), que contempla a aprovação das Políticas de Extensão da UNESC, apresenta a Instituição como um espaço aberto à comunidade e assume a extensão como oportunidade da comunidade acadêmica dialogar com a realidade social, proporcionando a conexão do ensino e da pesquisa (UNESC, 2015).

O documento menciona ainda que o impacto social esperado pelas atividades de extensão não se dá meramente por meio de qualificação, mas especialmente pelo processo de construção e de execução das demandas sociais que tenham como referencial a justiça social, a cidadania e a dignidade da pessoa humana (UNESC, 2015).

A gestão das atividades de extensão é efetuada pela Pró-Reitoria de Pós-Graduação, Pesquisa e Extensão (PROPEX), por meio da Assessoria de Extensão, sendo que as unidades 


\section{Revista de Extensão, v. 1, n. 2, 2016}

acadêmicas coordenam as atividades de ensino, pesquisa e extensão na sua área de atuação (UNESC, 2015).

O desenvolvimento da extensão da UNESC tem por objetivo promover a integração do conhecimento entre a Universidade e a sociedade, envolvendo a comunidade acadêmica em ações articuladas, interprofissionais e interinstitucionais, contribuindo para a consolidação da missão institucional (UNESC, 2015).

A relevância social da extensão é concebida em três eixos norteadores: a) a formação humana e técnica da comunidade acadêmica, na esteira do princípio da indissociabilidade com o ensino e a pesquisa; b) o compromisso com o empoderamento comunitário e com o desenvolvimento econômico, humano e social, em especial da área de atuação da instituição; c) o reconhecimento da importância de primar pelos princípios de sustentabilidade ancorada no tripé econômico, social e ambiental, em especial da área de atuação da instituição (UNESC, 2015).

$\mathrm{Na}$ UNESC, a extensão se efetiva por diversas formas, especialmente por meio de Programas Permanentes de Extensão, os quais congregam projetos, ações, cursos, eventos e prestação de serviço.

A organização dos Programas Permanentes de Extensão tem caráter orgânicoinstitucional, clareza de diretrizes e orientação para um objetivo comum, sendo executado a médio e longo prazo (FORPROEX, 2007). O Quadro 1 expõe as características desses elementos.

Quadro 1. Elementos dos Programas Permanentes de Extensão e suas características.

\begin{tabular}{|c|l|}
\hline Elementos & \multicolumn{1}{c|}{ Características } \\
\hline Universitária & $\begin{array}{l}\text { São ações processuais e continuadas de caráter educativo, social, cultural, científico } \\
\text { ou tecnológico, com objetivo específico e prazo determinado. Possibilitam a } \\
\text { formação de um elo entre a universidade e a sociedade. Podem ser desenvolvidos por } \\
\text { meio de edital institucional ou, ainda, projetos próprios, via fomento externo, } \\
\text { desenvolvidos com finalidades claras e objetivos específicos, apresentados ao } \\
\text { Colegiado da Unidade Acadêmica e/ou à PROPEX, para aprovação. }\end{array}$ \\
\hline Cursos de Extensão & $\begin{array}{l}\text { Ação pedagógica, de caráter teórico e/ou prático, presencial ou à distância, planejada } \\
\text { e organizada de modo sistemático, com carga horária mínima de 8 horas com função } \\
\text { de capacitação, atualização, aperfeiçoamento e treinamento. }\end{array}$ \\
\hline Eventos de Extensão & $\begin{array}{l}\text { Implica na apresentação e/ou exibição pública, livre ou com clientela específica, do } \\
\text { conhecimento ou produto cultural, artístico, esportivo, científico e tecnológico } \\
\text { desenvolvido, conservado ou reconhecido pela Universidade. }\end{array}$ \\
\hline Prestação de Serviços & $\begin{array}{l}\text { Caracteriza-se por atividade de serviços profissionais para as quais a Universidade } \\
\text { desenvolve conhecimento, atendendo as demandas de pessoas físicas e jurídicas, de } \\
\text { direito público ou privado, com recursos oriundos de convênios e/ou parcerias } \\
\text { institucionais, ou ainda através de oferta da própria instituição, mediante } \\
\text { contraprestação de terceiros ou não (FORPROEX, 2007). }\end{array}$ \\
\hline Ação Comunitária & $\begin{array}{l}\text { Ação realizada pela instituição baseada na dialogicidade entre parceiros } \\
\text { (Universidade e sociedade), na qual os sujeitos envolvidos constroem a cidadania. } \\
\text { Caracteriza-se pela realização de atividades de sensibilização e organização da }\end{array}$ \\
\hline
\end{tabular}


Revista de Extensão, v. 1, n. 2, 2016

\begin{tabular}{|c|l|}
\hline Elementos & \multicolumn{1}{|c|}{ Características } \\
\hline & $\begin{array}{l}\text { população, voltada ao resgate de seu papel de sujeito da própria história, que } \\
\text { favorecem o desenvolvimento social e a melhoria das condições do ambiente de } \\
\text { vida. }\end{array}$ \\
\hline Ação Voluntária & $\begin{array}{l}\text { Tem como objetivo divulgar a filosofia do trabalho voluntário, articuladas com } \\
\text { projetos de extensão, assim como estimular a participação social da comunidade } \\
\text { universitária em experiências de solidariedade social. }\end{array}$ \\
\hline $\begin{array}{l}\text { Publicações e Outros } \\
\text { Produtos Acadêmicos }\end{array}$ & $\begin{array}{l}\text { Caracterizam-se como a produção de publicações e produtos acadêmicos decorrentes } \\
\text { das ações de extensão, para difusão e divulgação cultural, científica ou tecnológica. }\end{array}$ \\
\hline
\end{tabular}

Fonte: Dados da pesquisa (2015).

Na UNACSA a extensão é realizada por meio de Programas Permanentes que preferencialmente integrem as atividades de extensão, pesquisa e ensino. Até o ano de 2015 a UNACSA possuía três Programas Permanentes de Extensão, que são: Programa de Ações em Economia Solidária (PAES), Programa de Extensão em Direito e Cidadania (PEDIC) e Programa de Orientação ao Pequeno Empreendedor (POPE), conforme apresenta o Quadro 2.

Quadro 2. Programas Permanentes de Extensão da UNACSA.

\begin{tabular}{|c|l|}
\hline PROGRAMA & \multicolumn{1}{|c|}{ CARACTERÍSTICAS/ DESCRIÇÃO } \\
\hline PAES & $\begin{array}{l}\text { Programa de cunho social, com atenção a sujeitos e comunidades em situação de pobreza } \\
\text { e vulnerabilidade social. Estratégias construídas sob perspectiva interdisciplinar, } \\
\text { direcionadas às categorias de inclusão produtiva, trabalho, emprego, sustentabilidade } \\
\text { ambiental, desenvolvimento organizacional e social, inseridos em diversas áreas de } \\
\text { atuação. }\end{array}$ \\
\hline PEDIC & $\begin{array}{l}\text { Programa que tem como tema central a discussão sobre a cidadania e o acesso a direitos } \\
\text { fundamentais e demais questões ou temáticas consagradas na legislação, cuja efetivação é } \\
\text { necessária para a emancipação dos indivíduos e da comunidade. Propõe-se a socialização } \\
\text { de informações e a discussão junto ao público assistido de temáticas relativas ao direito } \\
\text { da criança e do adolescente, direito do consumidor, direito do trabalho e previdenciário, } \\
\text { direito do idoso, direito de família e sobre violência doméstica e familiar, questões de } \\
\text { gênero, assistência judiciária aos reeducandos dos estabelecimentos penais, bem como o } \\
\text { encaminhamento das demandas individuais e coletivas identificadas a entidades aptas a } \\
\text { solucioná-las. }\end{array}$ \\
\hline POPE & $\begin{array}{l}\text { Visa oferecer assessoria e capacitações para microempreendedores criativos formais e } \\
\text { informais, com vistas a produzir autonomia na gestão e manutenção dos } \\
\text { empreendimentos, sustentados pela inovação contínua e responsabilidade social e } \\
\text { ambiental junto aos públicos vinculados às instituições parceiras. }\end{array}$ \\
\hline
\end{tabular}

Fonte: UNESC (2015).

Conforme determina a Política de Extensão da UNESC, a gestão dos Programas se dá de forma colegiada, envolvendo representantes dos projetos e de atividades de extensão, além da diretoria da UNACSA. O documento menciona ainda que é atribuição do colegiado indicar o coordenador dos Programas de Extensão, bem como definir a estrutura disponível para a execução das atividades (UNESC, 2015). 


\section{Revista de Extensão, v. 1, n. 2, 2016}

\subsection{A extensão no Curso de Ciências Contábeis da UNESC}

O Curso de Ciências Contábeis tem por objetivo viabilizar a formação de profissionais competentes, dinâmicos e empreendedores, como cidadãos participantes e responsáveis pela promoção do desenvolvimento sustentável da região, em seus aspectos econômico, social e ambiental.

Para tanto, emprega seus esforços junto aos estudantes com intuito de viabilizar a formação de profissionais com raciocínio lógico, crítico e analítico para a solução de problemas da área da contabilidade, despertar para a construção e reconstrução do conhecimento em ambientes de constantes mudanças, facilitar a formação de profissionais com capacidade de comunicação e liderança, dotando-os de habilidades e atitudes para promover e realizar trabalhos em equipe, além de estimular o desenvolvimento integrado e contínuo de competências (conhecimentos, habilidades e atitudes) necessárias ao profissional da Contabilidade.

Até o ano de 2015 o Curso realizava ações pontuais de extensão, como o Imposto de Renda na Praça, Contabilizando Saúde e Contabilizando Natal. Nos projetos de extensão, fomentado com recursos da Universidade e de convênios externos, a participação acontecia mediante iniciativas isoladas de professores e estudantes, como nos projetos do POPE (Programa de Orientação ao Pequeno Empreendedor) e do PAES (Programas de Ações em Economia Solidária).

Contudo, esses programas, embora mantenham projetos pertinentes à atribuição do Contador, não possuem maior identidade com a área contábil. Todavia, os estudantes do Curso de Ciências Contábeis não podem ficar restritos a mera compreensão dos textos das normas legais e profissionais ou da teoria contábil, pois o Contador necessita da dimensão prática por meio do contato com o exercício profissional e, também, com a realidade social.

Diante dos motivos expostos, a Coordenação do Curso, em consonância com o pensamento do Núcleo Docente Estruturante (NDE) e da UNACSA, incentivou a elaboração da proposta de um Programa de Extensão que levasse em consideração as especificidades do Curso e o perfil desejado ao egresso. Por meio do desenvolvimento de um Trabalho de Conclusão de Curso (TCC), no segundo semestre de 2015, foi elaborada a proposta do Programa, que atualmente é denominado: Programa de Extensão em Gestão Contábil (PEGC). 


\section{Revista de Extensão, v. 1, n. 2, 2016}

\subsection{O Programa de Extensão em Gestão Contábil - PEGC}

Em dezembro de 2015, em reunião com a Pró-Reitoria de Pós-Graduação, Pesquisa e Extensão e com a Unidade Acadêmica de Ciências Sociais Aplicadas, a proposta do Programa de Extensão em Gestão Contábil foi apresentada e de imediato aprovada, ficando ao encargo da UNACSA e da Coordenação do Curso de Ciências Contábeis dar condições para a efetividade do Programa.

Em fevereiro de 2016, durante uma cerimônia na UNACSA, foi dado posse à coordenadora do PEGC, por meio da Portaria 1/2016/UNACSA. A professora coordenadora possui titulação de mestre em Contabilidade com dedicação integral à academia, dispondo de 4 horas aula para atividades do PEGC, tendo o auxílio de uma aluna bolsista.

O PEGC tem o objetivo de apoiar pessoas físicas de baixa renda, sociedades civis sem fins lucrativos e micro e pequenas empresas sem acesso às orientações básicas da contabilidade. O Programa tem por objetivos específicos os seguintes:

Promover debates participativos, organizados por professores e estudantes dos Cursos da UNACSA e outros cursos afins da UNESC, sobre as temáticas propostas nos projetos de extensão;

$\checkmark \quad$ Unir as questões de cidadania com a prática pedagógica do Curso;

$\checkmark \quad$ Oportunizar capacitação diferenciada aos estudantes do Curso de Ciências Contábeis e demais cursos da UNACSA;

$\checkmark \quad$ Estreitar relacionamento com instituições, tais como: CRC/SC (Conselho Regional de Contabilidade de Santa Catarina), empresas prestadoras de serviços de contabilidade da região, contadores de entidades de natureza pública e/ou privada, Receita Federal do Brasil e outros órgãos de governo, em todas as suas esferas;

$\checkmark \quad$ Buscar parcerias com outras instituições a fim de captar recursos externos ao Programa;

$\checkmark \quad$ Identificar demandas individuais e coletivas para ampliar a atuação do programa na Universidade e fora dela; e

$\checkmark \quad$ Divulgar os resultados das práticas extensionistas.

As vantagens para os participantes da iniciativa do PEGC são inúmeras. A comunidade receberá atendimento na área da contabilidade, fato que oportuniza não só melhor retorno financeiro, mas também capacitação e qualificação pessoal e profissional e, sobretudo, o empoderamento social. 


\section{Revista de Extensão, v. 1, n. 2, 2016}

As empresas que prestam serviços de contabilidade poderão redirecionar ao PEGC casos mais simples, como, por exemplo, o cadastro de microempreendedores individuais. A Receita Federal e demais órgãos governamentais, enquanto parceiros do Programa, cumprirão seu papel referente à educação fiscal por via direta e de atendimento por via indireta. Os órgãos públicos poderão fazer uso das atividades do PEGC por meio de orientações referente à prestação de contas.

Para a UNESC, o PEGC é um dos meios para cumprir sua missão de educar, por meio do ensino, pesquisa e extensão, na melhoria da qualidade e da sustentabilidade do ambiente de vida, além do fortalecimento de sua imagem frente à comunidade onde se insere.

Por fim, os professores têm mais uma oportunidade de fazer a interlocução com o ensino e a pesquisa e de trabalhar de forma interdisciplinar. Os estudantes, participando ativamente nas ações do PEGC, terão oportunidade de conhecer a realidade social e contribuir para a melhoria das comunidades além de exercitar sua cidadania e aprimorar sua formação profissional.

Dentre o universo de temas possíveis de serem abordados, com base nas áreas temáticas contempladas na Política Nacional de Extensão Universitária: Comunicação, Cultura, Direitos Humanos e Justiça, Educação, Meio Ambiente, Saúde, Tecnologia e Produção e Trabalho e, considerando o público assistido, formado essencialmente por grupos organizados no âmbito da comunidade, o PEGC propõe-se, inicialmente, a apresentar projetos e ações pertinentes a áreas temáticas expostas no Quadro 3.

Quadro 3. Áreas Temáticas que envolvem os projetos e Ações do PEGC.

\begin{tabular}{|c|c|l|}
\hline Área Temática & Denominação & \multicolumn{1}{c|}{ Definição } \\
\hline \multirow{3}{*}{ Principal } & $\begin{array}{l}\text { Tecnologia e } \\
\text { Produção }\end{array}$ & $\begin{array}{l}\text { Transferência de tecnologias apropriadas; empreendedorismo; } \\
\text { empresas juniores; inovação tecnológica; polos tecnológicos; } \\
\text { capacitação e qualificação de recursos humanos e de gestores } \\
\text { de políticas públicas de ciências e tecnologia; cooperação } \\
\text { interinstitucional e cooperação internacional na área; direitos } \\
\text { de propriedade e patentes. }\end{array}$ \\
\hline \multirow{5}{*}{ Secundária } & Trabalho & $\begin{array}{l}\text { Reforma agrária e trabalho rural; trabalho e inclusão social; } \\
\text { capacitação e qualificação de recursos humanos e de gestores } \\
\text { de políticas públicas do trabalho; cooperação interinstitucional } \\
\text { e cooperação internacional na área; educação profissional; } \\
\text { organizaçóes populares para o trabalho; cooperativas } \\
\text { populares; questão agrária; saúde e segurança no trabalho; } \\
\text { trabalho infantil; turismo e oportunidades de trabalho. }\end{array}$ \\
\hline
\end{tabular}

Fonte: Adaptado da Política Nacional de Extensão (2015).

O PEGC tem por escopo o fortalecimento do vínculo teoria e prática do exercício profissional dos acadêmicos do Curso de Ciências Contábeis, proporcionando aprendizado prático por meio do contato direto com a realidade local. 
Para tanto, o Programa inscreveu alguns projetos de extensão para concorrer às vagas no Edital 22/2015/UNACSA. O edital, aberto em dezembro de 2015, objetivou selecionar 12 projetos entre os Programas Permanentes de Extensão da UNACSA (POPE, PAES, PEDIC e PEGC), que tivessem inserção na realidade social, visando estimular e garantir o envolvimento acadêmico na discussão e encaminhamentos das demandas da comunidade. $\mathrm{O}$ período de execução dos projetos aprovados está compreendido entre fevereiro de 2016 e março de 2018.

Seis projetos foram submetidos pelo PEGC no Edital 22/2015/UNACSA, a saber: a) PDLJOVEM - Programa de Desenvolvimento Lideranças Jovens: o empreendedorismo social para melhorar o ambiente de vida da geração atual e futura; b) Projeto Acolhida - ações voltadas a legalização e organização de instituições de longa permanência para idosos (ILPI) no município de Criciúma-SC; c) Desenvolvimento de Carreiras: do autoconhecimento à definição do caminho na profissão escolhida; d) Educar para Empreender (EPE); e) Programa de assessoria e consultoria contábil e organização das associações de pais e professores (APP's) da rede pública municipal; e f) Planejamento e controle de custos para formação do preço justo de vendas.

Dos seis projetos submetidos ao Edital, dois foram aprovados:

a) Planejamento e controle de custos para formação do preço justo de vendas, com objetivo de desenvolver metodologia que oportunize a gestão de custos e formação do preço de venda justo aos empreendimentos participantes da Feira da Economia Solidária da UNESC; e

b) Programa de assessoria e consultoria contábil e organização das associações de pais e professores - APP's da rede pública municipal, com o objetivo de apoiar, por meio de orientação, assessoria e consultoria contábil, às APP's da rede pública municipal de Siderópolis-SC.

Cada projeto recebeu fomento da Universidade no valor de $\mathrm{R} \$ 4.000,00$ para dois anos, e abrange 4 horas semanais para professores e bolsas para estudantes. Há possibilidade também do PEGC receber a contribuição de trabalho voluntário de professores e estudantes, sendo que estes últimos receberão certificados de extensão os quais poderão utilizar para computo de horas de Atividades de Formação Complementar. 
4.3.1 As ações do PEGC: o diálogo entre universidade e comunidade

A primeira ação realizada pelo PEGC foi colaborar com a coordenação do Curso de Ciências Contábeis/UNESC na organização do "Projeto Imposto de Renda na Praça", que acontece anualmente, no mês de abril, na Praça Nereu Ramos no município de Criciúma-SC.

A ação tem por objetivo sanar dúvidas da comunidade sobre o correto preenchimento da Declaração do Imposto de Renda Pessoa Física e sobre as doações para o Fundo para a Infância e Adolescência de Criciúma (FIA). O evento tem a parceria da prefeitura de Criciúma, por meio da Secretaria de Assistência Social, é realizado há seis anos e nas edições de 2014, 2015 e 2016 foram efetuados 37, 68 e 74 atendimentos à comunidade, respectivamente.

Outra iniciativa do PEGC foi a apresentação do Projeto Planejamento e Controle de Custos para Formação do Preço Justo de Vendas durante a realização do Fórum de Economia Solidária da UNESC, também em abril de 2016.

$\mathrm{O}$ evento contou com a presença dos integrantes do projeto de extensão Ações para Continuidade da Feira de Economia Solidária da UNESC e Fortalecimento do Fórum de Economia Solidária da Região Sul Catarinense, de representantes da Vigilância Sanitária de Criciúma, do representante da Empresa de Pesquisa Agropecuária e Extensão Rural de Santa Catarina (EPAGRI) e da Cáritas Diocesana.

Nessa ocasião, sete integrantes da Feira de Economia Solidária da UNESC mostraram interesse em gerenciar os custos de seus empreendimentos, integrando assim ao projeto Planejamento e Controle de Custos para Formação do Preço Justo de Vendas.

O Fórum de Economia Solidária da UNESC ocorre mensalmente e preferivelmente na primeira quarta-feira de cada mês. Até o momento, o PEGC se fez presente nos 5 fóruns realizados no ano de 2016, a fim de aproximar-se do público-alvo do projeto, verificar as demandas e orientar os empreendedores no que se refere ao registro dos dados de fabricação de seus produtos.

Como resultado dessas participações, o Programa realizou em maio de 2016 a "Oficina Custo Social: formação do preço justo de vendas", atendendo à solicitação dos membros da feira de Economia Solidária da UNESC. Ao todo, 16 feirantes compareceram ao evento, que teve por objetivo capacitá-los acerca do cálculo para formação do preço de vendas. 


\section{Revista de Extensão, v. 1, n. 2, 2016}

O PEGC apoiou a realização da Exposição Conhecer para Preservar, ação de extensão empreendida na disciplina de Contabilidade, Meio ambiente e Responsabilidade Social, da $4^{\mathrm{a}}$ fase do Curso de Ciências Contábeis, realizada no mês de junho de 2016.

A exposição propõe despertar a visão crítica a respeito da responsabilidade social corporativa. Esta edição teve como tema a "Responsabilidade Social Corporativa: as questões da Dengue, Zyka e Chicungunya e o acidente ambiental de Mariana/MG”.

A I Mostra Científica de Projetos Acadêmicos de Ciências Contábeis foi outra ação promovida pelo Programa que reuniu acadêmicos e professores do curso, bem como demais interessados, com o propósito de socializar as pesquisas científicas elaboradas pelos estudantes da $8^{a}$ fase durante o primeiro semestre de 2016. A extensão manifestou-se, ao passo que promoveu a divulgação das pesquisas à comunidade em geral e oportunizou a troca de conhecimentos entre os envolvidos.

Em consonância com seus objetivos, o PEGC realizou no mês de junho a ação Contabilidade Solidária, que teve como público-alvo entidades sem fins lucrativos da região. No evento foram apresentadas propostas de controles financeiros em planilhas eletrônicas (Excel), prática importante para a administração dessas instituições.

Essa ação dialoga com outras duas ações da Universidade - Projeto Solidariedade e a disciplina de Contabilidade Intermediária por meio da Atividade Prática Específica (APE) -, ambas desenvolvidas na $3^{\text {a }}$ fase do Curso.

Atendendo à demanda da comunidade, para o segundo semestre de 2016 está planejada a realização de um minicurso acerca da gestão dos Centros Acadêmicos. Em parceria com o Diretório Central dos Estudantes (DCE) da UNESC, a ação visa capacitar atuais e futuros líderes estudantis para um melhor gerenciamento desses Centros.

Além do debate entre os organizadores e o público-alvo, durante o evento será lançada uma cartilha com o propósito de explicar e ilustrar de maneira simples e didática as atividades a serem desempenhadas pelos membros dos Centros Acadêmicos.

\section{CONSIDERAÇÕES FINAIS}

A UNESC, enquanto universidade comunitária, assume a extensão como dimensão que proporciona aos professores e estudantes o contato com a realidade social favorecendo a articulação do ensino e da pesquisa gerando alternativas de ação que atendem os problemas da população além de ser um espaço para o exercício da emancipação crítica da comunidade acadêmica e da sociedade. 
A Universidade organiza a extensão, quando possível, por meio de Programas Permanentes, os quais congregam um conjunto articulado de projetos, cursos, eventos, ação comunitária e prestação de serviços, constituindo-se em espaços de interlocução com ensino e pesquisa, envolvendo professores, acadêmicos e comunidade.

O Curso de Ciências Contábeis propõe-se como forma de aproximar professores e estudantes com a comunidade oportunizando a troca de saberes, um Programa Permanente de Extensão que atenda as especificidades do Curso e da região. A proposta do programa, denominado Programa de Extensão em Gestão Contábil, objetiva apoiar pessoas físicas de baixa renda, sociedade sem fins lucrativos e micro e pequenas empresas sem acesso às orientações básicas da contabilidade.

Para o sucesso do Programa, faz-se necessário olhar para o Projeto Pedagógico do Curso e sua matriz curricular, com intuito de compor linhas de extensão alinhadas à sua missão e ao perfil desejado para o egresso e captar professores e estudantes com desejo de construir um saber mais reflexivo, voltado para a vida comunitária, oportunizando a formação de estudantes, não só competentes profissionalmente, mas também conscientes de sua cidadania e comprometidos com a transformação social.

Em 2016, no primeiro ano de atuação, o PEGC desenvolveu atividades expressivas na busca da construção do elo entre universidade-comunidade. Considerando o pouco tempo de sua existência, nota-se que as ações Imposto de Renda na Praça, participação nos Fóruns de Economia Solidária, Oficina Custo Social, Exposição Conhecer para Preservar, Mostra Científica de Projetos Acadêmicos de Ciências Contábeis e Contabilidade Solidária foram essenciais ao alcance dos objetivos do fazer extensão universitária, no âmbito das Ciências Contábeis.

Contudo, cientes do longo caminho que o Curso de Ciências Contábeis tem a percorrer para fomentar projetos e ações extensionistas por meio do PEGC, inclusive no aprofundamento das discussões sobre a inserção da extensão na matriz curricular, torna-se mister cooptar novos professores e estudantes com desejo de construir um saber mais reflexivo.

\section{REFERÊNCIAS}

BRASIL. Decreto 19.851, de 11 de abril de 1931. Dispõe que o ensino superior no Brasil obedecerá, de preferência, ao systema universitario, podendo ainda ser ministrado em institutos isolados, e que a organização technica e administrativa das universidades é instituida no presente Decreto, regendo-se os institutos isolados pelos respectivos regulamentos, observados os dispositivos do seguinte Estatuto das Universidades Brasileiras. 
Disponível em: <http://www2.camara.leg.br/legin/fed/decret/1930-1939/decreto-19851-11abril-1931-505837-publicacaooriginal-1-pe.html>. Acesso em: 20 mar. 2016.

BRASIL. Lei 5.540, de 28 de novembro de 1968. Fixa normas de organização e funcionamento do ensino superior e sua articulação com a escola média, e dá outras providências. Disponível em: <http://www.planalto.gov.br/ccivil_03/leis/L5540.htm>. Acesso em: 20 mar. 2016.

CABRAL, N. C. Saberes em Extensão Universitária: contradições, tensões, desafios e desassossegos. 2012. 259 f. Tese (Doutorado) - Universidade Federal do Rio Grande do Sul, Porto Alegre, RS, 2012.

FORPROEX, Extensão Universitária: organização e sistematização. Fórum de PróReitores de Extensão das Universidades Públicas Brasileiras. Belo Horizonte: Coopmed, 1987.

FORPROEX II, Extensão Universitária: organização e sistematização / Fórum de PróReitores de Extensão das Universidades Públicas Brasileiras. Coordenação Nacional do FORPROEX. Belo Horizonte: Coopmed, 2007.

GIL, A. C. Como elaborar projetos de pesquisa. 4. ed. São Paulo: Atlas, 2002. OLIVEIRA, S. L. Tratado de metodologia científica: projetos de pesquisas, TGI, TCC, monografias, dissertações e teses. 2. ed. São Paulo: Pioneira, 1997.

PINHEIRO, J. M. dos S. Da Iniciação Científica ao TCC: uma abordagem para os cursos de tecnologia. Rio de Janeiro: Editora Ciência Moderna, 2010.

PLANO Nacional Extensão Universitária. Renex: Coleção Extensão Universitária FORPROEX, vol. 1. Disponível em: <http://www.renex.org.br/documentos/ColecaoExtensao-Universitaria/01-Plano-Nacional-Extensao/Plano-nacional-de-extensaouniversitaria-editado.pdf >. Acesso em: 19 mai. 2015.

SILVA, A. R. A contribuição da Extensão na formação do estudante Universitário. 2011. 96 f. Dissertação (Mestrado) - Universidade Católica de Brasília, Brasília, 2011.

SILVA, M. B.; GRIGOLO, T. M. Metodologia para iniciação científica a prática da pesquisa e da extensão II. Caderno Pedagógico. Florianópolis: Udesc, 2002.

UNIVERSIDADE DO EXTREMO SUL CATARINENSE - UNESC. Resolução n. 12/2015/CONSU. Políticas de Extensão da Unesc. 2015. Disponível em: <http://www.unesc.net/portal/resources/documentosoficiais/11863.pdf?1438697836>. Acesso em: 01 jan. 2015. 